\title{
A New Look at Cardiac Defense: Attention or Emotion?
}

\author{
Jaime Vila, María Carmen Fernández, Joaquín Pegalajar, María Nieves Vera, Humbelina \\ Robles, Nieves Pérez, María B. Sánchez, Isabel Ramírez, and Elisabeth Ruiz-Padial \\ University of Granada
}

The study of cardiac defense has a long tradition in psychological research both within the cognitive approach-linked to Pavlov, Sokolov, and Graham's work on sensory reflexes-and within the motivational one-linked to the work of Cannon and subsequent researchers on the concepts of activation and stress. These two approaches have been difficult to reconcile in the past. We summarize a series of studies on cardiac defense from a different perspective, which allows integration of the traditional approaches. This new perspective emphasizes a sequential process interpretation of the cardiac defense response. Results of descriptive and parametric studies, as well as those of studies examining the physiological and psychological mechanisms underlying the response, show a complex response pattern with both accelerative and decelerative components, with both sympathetic and parasympathetic influences, and with both attentional and emotional significance. The implications of this new look at cardiac defense are discussed in relation to defensive reactions in natural settings, the brain mechanisms controlling such reactions, and their effects on health and illness.

Keywords: heart rate, defense reflex, startle reflex, attention, emotion, stress

El estudio de la respuesta cardiaca de defensa tiene una larga tradición en la investigación psicológica, tanto desde la perspectiva cognitiva -vinculada a los trabajos de Pavlov, Sokolov y Graham sobre los reflejos sensoriales-, como desde la perspectiva motivacional-vinculada a los trabajos de Cannon e investigadores posteriores, sobre los conceptos de activación y estrés-. Estas dos perspectivas han sido difíciles de integrar en el pasado. El presente artículo resume una serie de estudios sobre la respuesta cardiaca de defensa, desde una perspectiva diferente, que permite integrar las dos aproximaciones tradicionales. La nueva perspectiva hace hincapié en una interpretación procesual y secuencial de la respuesta cardiaca de defensa. Los resultados de estudios descriptivos y paramétricos, junto con los de estudios que examinan los mecanismos fisiológicos y psicológicos subyacentes a la respuesta, ponen de manifiesto un patrón complejo de cambios cardiacos en los que aparecen componentes tanto acelerativos como desacelerativos, con influencias simpáticas y parasimpáticas, y con significación tanto atencional como emocional. Las implicaciones de esta nueva visión de la respuesta defensiva del corazón se discuten en relación con la defensa en contextos naturales, los mecanismos cerebrales que controlan tales reacciones y sus efectos sobre la salud y la enfermedad.

Palabras clave: tasa cardiaca, reflejo defensivo, reflejo de sobresalto, atención, emoción, estrés

The series of studies reported in this article was supported by various research grants from the Spanish Ministry of Education (PR82/1933; PB93-1096; PB97-0841 \& BSO2001-3211) and the Junta de Andalucía (HUM-388).

Correspondence concerning this article should be addressed to Jaime Vila, Departamento de Personalidad de Evaluación y Tratamiento Psicológico, Facultad de Psicología, Campus La Cartuja s/n, 18011 Granada (Spain). E-mail: jvila@ugr.es 
The origin of the concept of defense is linked to the idea that organisms react physiologically to the presence of danger or threat. This reactivity has a protective function, since it provides the logistical and instrumental basis for adaptive behaviors such as fight or flight. However, if maintained for long periods, this protective or defensive reactivity may come to constitute a health risk, compromising the normal functioning of the organs involved. For many researchers, excessive physiological reactivity is the main mechanism linking defense to stress and illness.

The historical antecedents of these concepts are rooted in the work of Pavlov (1927) and Cannon (1929). At the beginning of the twentieth century, Pavlov and other Russian reflexologists used the term defense reflex to refer to protective physiological responses elicited by noxious stimulation, such as hand withdrawal to an electric shock, eye blink to a puff of air, or vomit to bad food. A few years later, Cannon used the term defense to refer to the fight or flight response, a sympathetically-mediated cardiovascular response to emergency situations aimed at providing energy supply to the body to facilitate adaptive behaviors such as attack or escape. By the middle of the last century, and following Cannon's ideas, Selye (1956) had introduced the concept of stress and used the term alarm response to refer to the first stage of the physiological response to stressful situations.

Subsequent research on the defense response has been extensive throughout the twentieth century. Two major psychophysiological approaches, both emphasizing the cardiovascular components, can be identified: the cognitive approach and the motivational approach. The cognitive approach, built on Pavlov's (1927) distinction between orienting and defense, assumes that cardiac changes in response to environmental stimuli reflect attentional and perceptual mechanisms aimed at facilitating or inhibiting the processing of the stimuli. The orienting response (a deceleration of the heart rate to moderate or novel stimulation) facilitates attention and perception of the stimuli, whereas the defense response (an acceleration of the heart rate to intense or aversive stimulation) reduces attention and perception as a form of protection against the aversive stimuli. In this context, the orienting-defense distinction proposed by Sokolov (1963) and Graham (1979) is equivalent to the intake-rejection distinction proposed by Lacey and Lacey (Lacey \& Lacey, 1970, 1974).

The motivational approach, built on Cannon's ideas on the fight and flight response, assumes that cardiac changes in response to environmental demands reflect metabolic mechanisms aimed at providing the body with the energy necessary to support behavioral adjustments (Obrist, 1981). If the appropriate behavior is to be passive and quiet, then the cardiac response will be a heart rate deceleration. If the appropriate behavior is to be active, either physically or psychologically, then the cardiac response will be a heart rate acceleration. To study cardiac defense, this approach has mainly used tasks that involve emotionally or cognitively challenging situations such as pressing a key as fast as possible to avoid shocks, or doing complex arithmetic tasks. The term mental stress was introduced in this context to refer to tasks that require mental effort rather than physical effort (Steptoe \& Vögele, 1991).

The cognitive and motivational approaches to cardiac defense have been difficult to reconcile in the past. However, in recent years new data have been accumulated on defense responses, both in animals and humans, and on the neurophysiological brain circuits controlling such responses, which not only facilitate integration of the classic approaches but also have potential implications for the concept of stress and stress-related illnesses. The classic model of cardiac defense assumes the following characteristics:

a) The response is a heart rate acceleration peaking at 3-6 seconds after stimulus onset.

b) The eliciting stimulus can be of any sensory modality but must be of high intensity $(>95 \mathrm{~dB})$, long duration $(>500$ $\mathrm{ms}$ ) and long rise time ( $>24 \mathrm{~ms}$ ), to differentiate the cardiac defense response from cardiac startle, which also requires high intensity, but shorter duration and shorter rise time.

c) The response shows slow habituation with repeated stimulation.

d) Its physiological mediation is exclusively sympathetic.

e) Its functional significance is a decrease in sensory processing as a form of protection against the stimulus.

This set of characteristics appears in almost all texts dealing with psychophysiological reflexes. The idea that orienting is the opposite of defense, and that cardiac deceleration is indicative of orienting and cardiac acceleration indicative of defense, is widely repeated. However, since the early 1940s there have been several reports challenging the view that the heart rate response to intense unexpected noises is a simple acceleration that shows a slow habituation and is sympathetically mediated. Bond, a student of Cannon, published in 1943 an article entitled Sympathetic and vagal interaction in emotional responses of the heart rate, in which he describes in dogs and cats a response pattern to intense noises with accelerative and decelerative components and with sympathetic and vagal mediation. His description is an illustration of the type of response that has since been reported in humans (Bond, 1943):

Intact dogs gave a remarkably constant response to a startling stimulation (noise made by hitting a table top with an iron rod 3 or 4 times in less than 2 seconds, or by a pistol shot). Variations were small, and when they occurred they were usually repeatedly demonstrable for the individual. The response began, within one-fifth of a second or less, with a 
loss of the respiratory rhythm and of the pulse, and an increasing heart rate, which progressed, with interruptions, to a maximum reached in 3 to 4 seconds. The rate of individual beats at this peak was 225 per minute or over (resting level was between 60 and $100 \mathrm{bpm}$ ) and was maintained for 4 to 6 seconds. At this point the heart rate usually fell toward the control level, sometimes crossing it. Characteristically, this fall was sudden and began with one or more very slow beats, ordinarily lasted about 10 seconds, and was succeeded by either a flattening at this level or a significant rise, on a slope more gradual than that of the initial rise, which reached a peak, variable in height, at 45 to 60 seconds after the stimulus (20 to 40 seconds for cats). From this time onward undulations in the rate, sometimes at quite regular intervals, were common. All evidence of the response usually disappeared within 2 to 3 minutes. (p. 89; the information in brackets refers to other parts of the article).

Similar reports questioning the intensity of the stimulus and the slow habituation as defining characteristics of defense have also been published (Eves \& Gruzelier, 1984, 1985; Turpin, 1986; Turpin \& Siddle, 1978; 1983). In general, these reports show clear evidence of an extremely rapid habituation of the response pattern, contrary to the expected slow habituation. The intensity issue has received more empirical support (Turpin, 1986), though there is no agreement on the intensity level that differentiates the orienting from the defense reflex, nor has research been carried out into the effect of intensity in different sensory modalities. The auditory modality has received most attention, followed by the electrocutaneous modality. The visual modality has rarely been studied in the context of defense (Belkic, 1986), except in the form of complex visual stimuli, such as slides showing accidents, phobic animals, or mutilated bodies (Hare, 1973; Klorman, Weissbert, \& Wiesenfeld, 1977; Lang, Bradley, \& Cuthbert, 1997). Finally, with regard to the physiological mediating mechanisms assumed by the classic modelsympathetic versus vagal-and the functional significance of the cardiac response-attentional versus motivationalthere is a lack of systematic research focused on the response to intense physical stimulation (see Coles, Jennings, \& Stern, 1984).

Recent research on defensive behaviors in animals has also presented a critical view with regard to the classic model of cardiac defense (Blanchard \& Blanchard, 1989; Fanselow, 1994; Fendt \& Fanselow, 1999; Lang, Bradley, \& Cuthbert, 1997; Lang, Davis, \& Öhman, 2002). In natural settings, such as that related to the imminence of a predator, defensive behavior changes as a function of the distance from the predator or other potentially dangerous stimulus. Thus, depending on the proximity of the danger, the defense reaction tends to follow a sequential process, with initial phases in which aversively-motivated attentional factors predominate, aimed at detection and analysis of the potential danger, and later phases in which aversively-motivated protective actions predominate, aimed at active defense such as fight or flight. This sequential process approach to defense is also supported from recent neurophysiological studies on fear and anxiety (see Davis, 1996; LeDoux, 1996, 2000). Neuroscience research with animals has repeatedly implicated the amygdala as a major center for the defense system involved in the expression and learning of fear. More recent research has demonstrated the role that the bed nucleus of stria terminalis - a part of the so-called extended amygdala-plays in anxiety, a more generalized and sustained fear response, distinct from cuespecific fear (Lang, Davis, \& Öhman, 2002). Both structures receive sensory information from the basolateral nucleus of the amygdala and project to various hypothalamic sites, the central gray, and brainstem target areas that directly mediate the specific responses characterizing fear and anxiety, e.g., freezing and hypervigilance, autonomic reactions, increased startle, facial expressions of fear, anticipatory apprehension, or defensive actions. These various outputs may be stages in the normal defense reaction of mammals, with an attentional set dominant when threat is more remote, but giving way to defensive actions with greater imminence of the aversive event (Lang, Davis, \& Öhman, 2002).

In spite of the above explicit and implicit criticisms of the classic model of cardiac defense, little systematic research has been conducted in humans to try and identify the specific features of heart rate response to an aversive physical stimulus such as an intense noise or an electric shock. Both types of stimulation are by far the most frequently used in both animal and human studies on aversive reactivity, habituation, and conditioning. Moreover, intense acoustic stimulation, in addition to being the preferred choice in human conditioning studies (Öhman, Hamm, \& Hugdahl, 2000), is the most common aversive stimulation in natural settings, its negative effects on health and psychopathology being well documented in the scientific literature (Kryter, 1970; Schell \& Lieberman, 1981; Vera, Vila, \& Godoy, 1994; Watson \& Rayner, 1920). The aim of the present article is to summarize the research we have been conducting over the last two decades on the cardiac defense response using as basic paradigm the presentation of an intense noise under different stimulus and task conditions. The series of studies we summarize were designed to answer the following questions: (a) What is the description of the heart rate response to an intense acoustic stimulus?; (b) What are the parametric characteristics of the eliciting stimulus in terms of sensory modality, intensity, duration, and rise time?; (c) What are the physiological mechanisms underlying the observed heart rate response?; and (d) What are the psychological processes involved in such a response? 


\section{Methodology and Results}

The studies we summarize below were all conducted with volunteer students. Specific details on number of participants, design, apparatus, procedures, and statistical analysis for each study can be found in the corresponding references. Here we simply present a brief description of the design, the procedure, and the significant results obtained. In general, all studies used a mixed factorial design with one or two between-group factors (usually the main independent variables) and one or two repeated-measures factors (usually the successive trials and the form of the physiological response). The test of the cardiac defense response was always the same: (a) a non-stimulation period of several minutes; (b) presentation of the first noise; (c) minimum inter-stimulus interval of around two minutes; and (d) subsequent presentations of the same noise with various inter-stimulus intervals. Depending on the aim of the study, this basic procedure could be modified by manipulating the parametric characteristics of the stimulus or over-imposing a secondary task (a memory task, an attentional task, or an emotional task). The main dependent variable was always the beat-by-beat heart rate response recorded from the electrocardiogram. In addition, other physiological, behavioral, and subjective measures were recorded, depending on the study. Additional physiological measures were respiration, pulse amplitude, blood pressure, and electromyography of orbicularis oculi. Additional behavioral measures were reaction time and number of hits and errors in the secondary tasks. Additional subjective measures were self-report of intensity and unpleasantness of the noise and assessment of the affective stimuli used in the secondary emotional task.

\section{Description of the response pattern}

Figure 1 shows, in the bottom row, the beat-by-beat heart rate response of one participant to three presentations of an intense noise (109 dB of $500 \mathrm{~ms}$ duration and instantaneous rise time) with an inter-stimulus interval of 95 seconds and an adaptation period prior to the first noise of 10 minutes. The top row represents the respiration and the middle row the blood pulse amplitude recorded from the finger. In the bottom row, one can clearly appreciate the presence of a complex heart rate response to the first noise, with two large accelerative components, one of short and the other of long latency. The rapid habituation of the second accelerative component is also evident in this representation.

Figure 2 plots the average heart rate response of a group of 15 participants to the first presentation of the stimulus, expressed in terms of second-by-second HR changes with respect to baseline (top figure), and provides a simplified representation of the same response based on 10 points corresponding to the medians of 10 progressively longer intervals (bottom figure): 2 of $3 \mathrm{~s}, 2$ of $5 \mathrm{~s}, 3$ of $7 \mathrm{~s}$, and 3 of $13 \mathrm{~s}$. From these data, it is clear that the response within the $80 \mathrm{~s}$ following stimulus onset is not a heart rate acceleration, but rather a complex pattern with two accelerative and two decelerative components in alternating order.

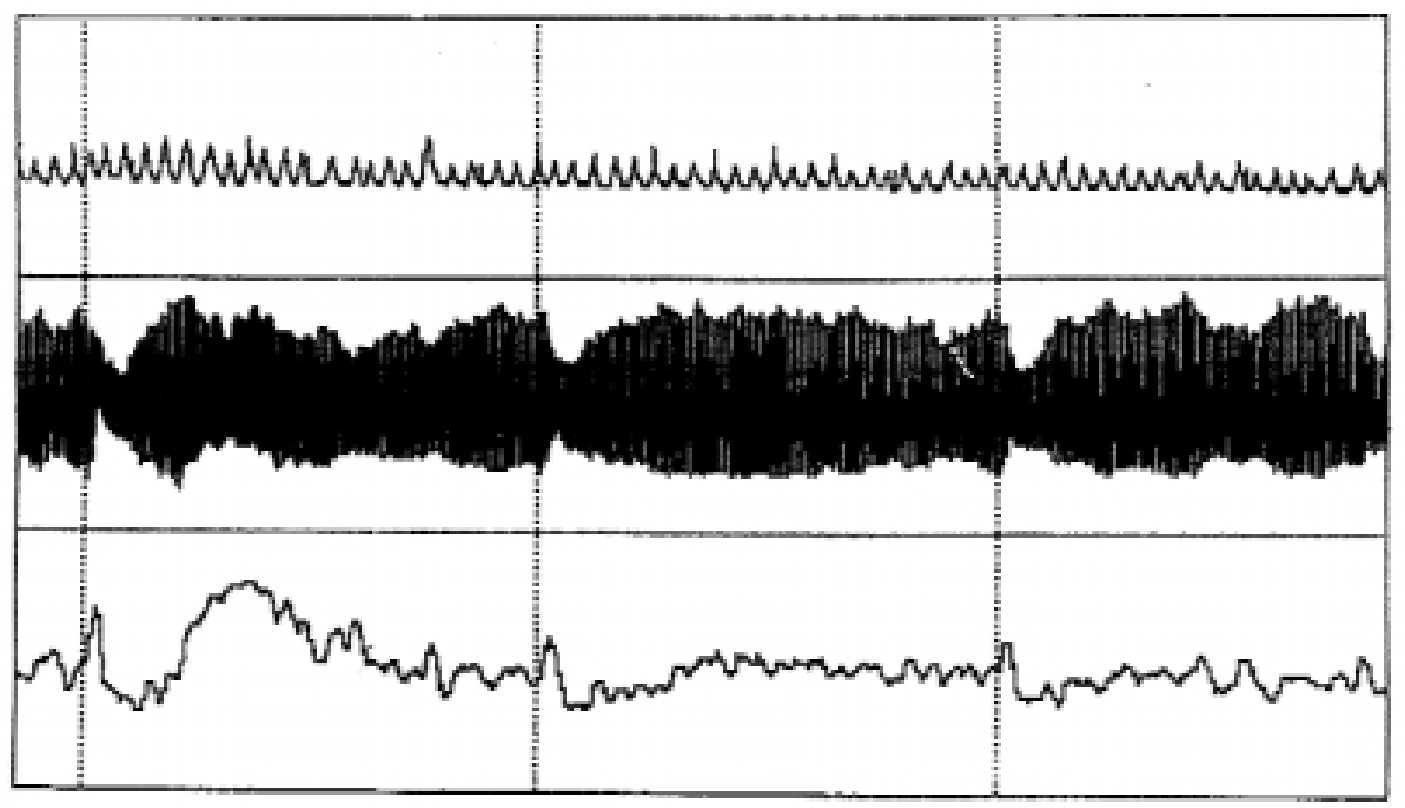

Figure 1. Recording of respiration (top), blood pulse amplitude (middle), and heart rate (bottom) in one participant during three presentations of an intense noise (vertical lines). 

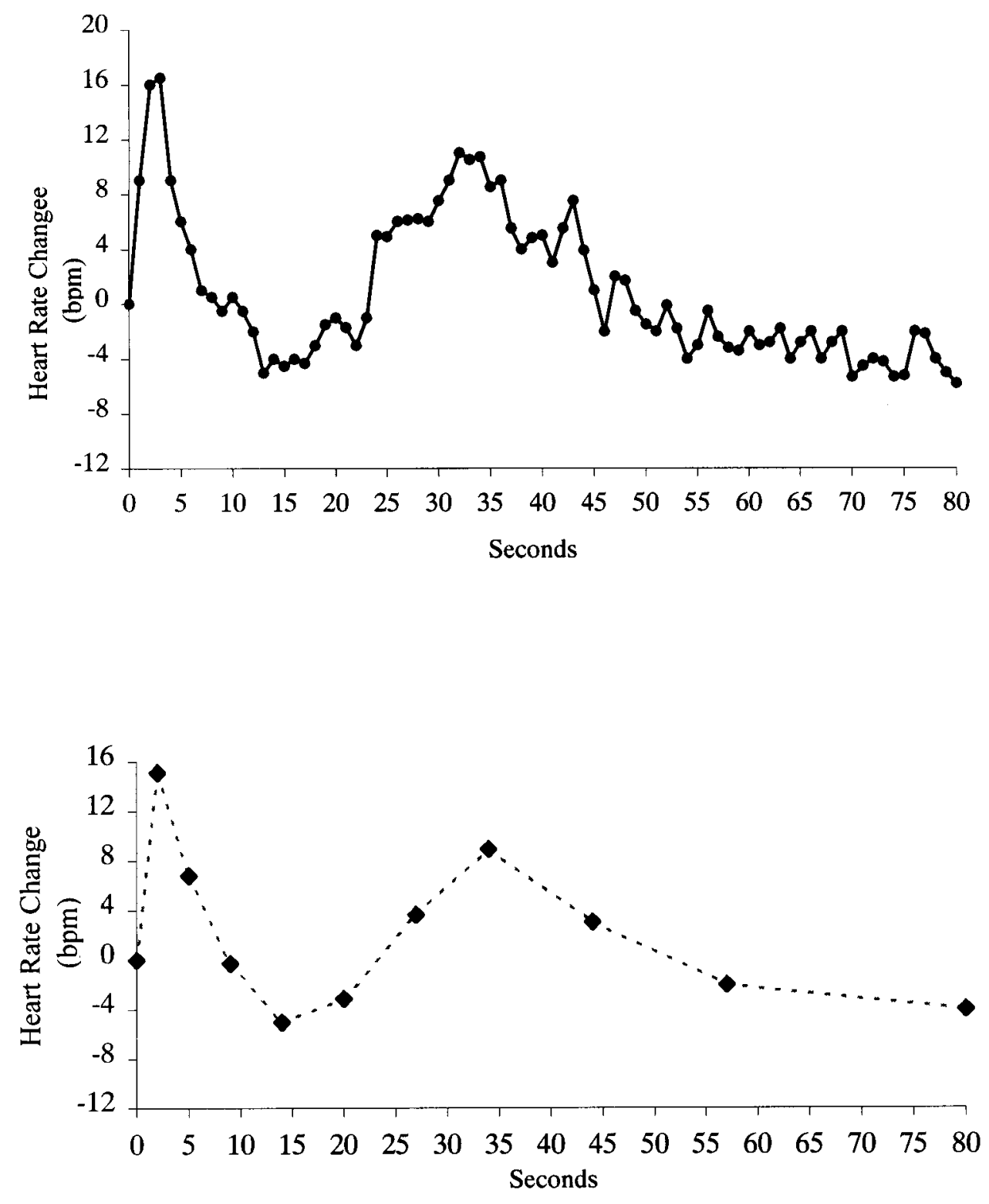

Figure 2. Average second-by-second heart rate response of 15 participants to the first presentation of the intense noise (top), and the same data expressed in terms of medians of 10 intervals (bottom).

\section{Stimulus characteristics}

Four stimulus parameters have been systematically studied: sensory modality (auditory, visual, and electrocutaneous), intensity, duration, and rise time (Vila \& Fernández, 1989; Vila, Fernández, \& Godoy, 1992; Vila, Sánchez, Ramírez, \& Fernández, 1997). A comparison of three sensory modalities (auditory, visual, and electrocutaneous), matched in intensity, shows that only the auditory and electrocutaneous modalities elicited the cardiac defense response (see Figure 3). The visual modality did not. On the other hand, intensity is not the only factor eliciting the response. At high intensity $(109 \mathrm{~dB})$ the accelerative components are larger. At moderate intensity $(79 \mathrm{~dB})$ the accelerative components are smaller but the full pattern is still present (Figure 3). 

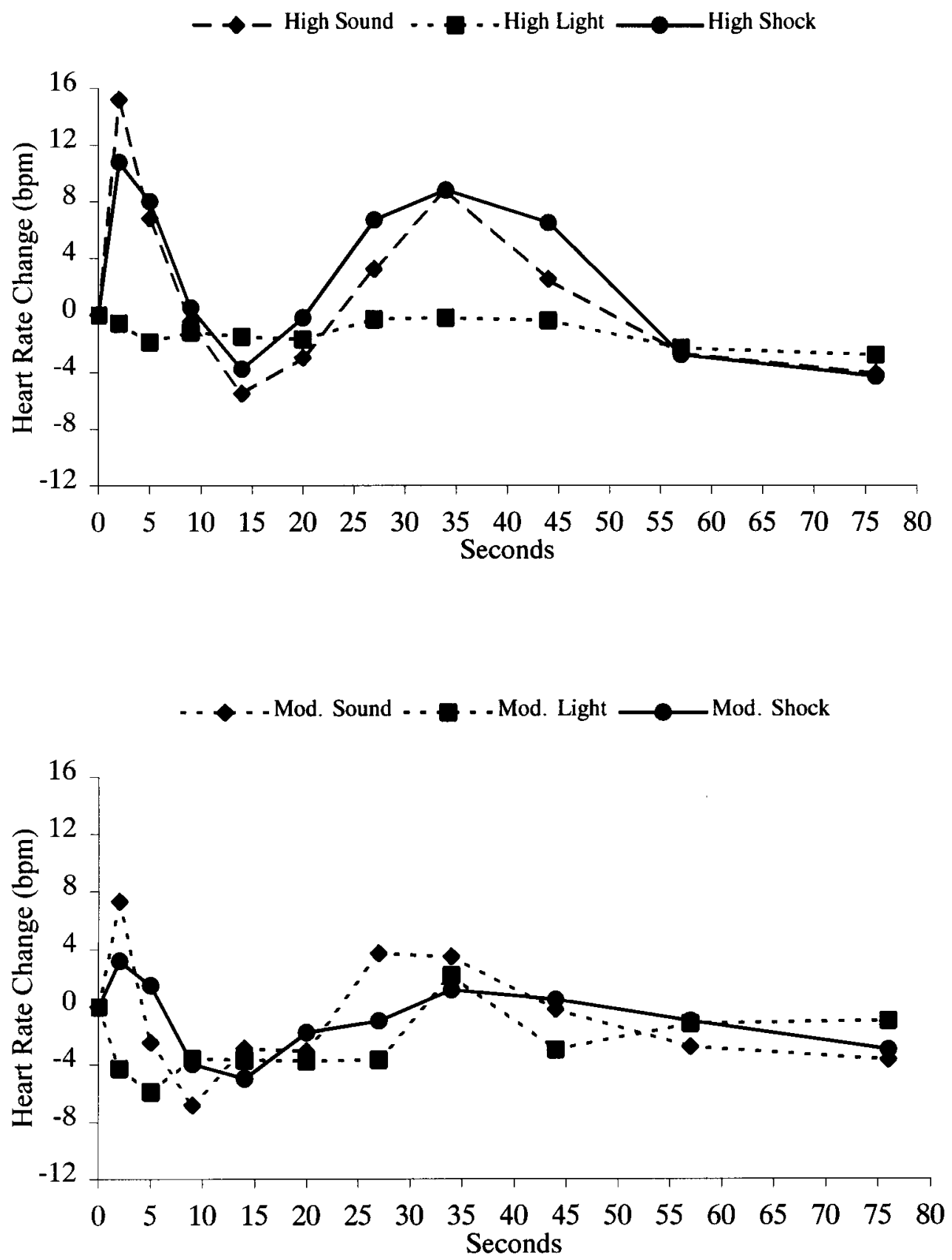

Figure 3. Cardiac Defense Response as a function of sensory modality (auditory, visual, and electrocutaneous) and of stimulus intensity (high and moderate).

Two other studies examined the duration and rise time of the eliciting stimulus. The duration of the stimulus (white noise of $105 \mathrm{~dB}$ and instantaneous rise time, manipulated at 5 stimulus durations: 50, 100, 250, 500, and $1000 \mathrm{~ms}$ ) affects the amplitude of the first and second accelerative components of the cardiac response (see Figure 4): the first acceleration increases linearly as a function of duration (from
$50 \mathrm{~ms}$ to $500 \mathrm{~ms}$ ), whereas the second acceleration was present only in the two longest duration conditions $(500 \mathrm{~ms}$ and $1000 \mathrm{~ms}$ ). Finally, the rise time of the stimulus (white noise of $105 \mathrm{~dB}$ and $1000 \mathrm{~ms}$ duration manipulated at 5 different rise times: $0,24,48,96$, and $240 \mathrm{~ms}$ ) has no effect at all on the amplitude of any of the cardiac components (see Figure 5). 


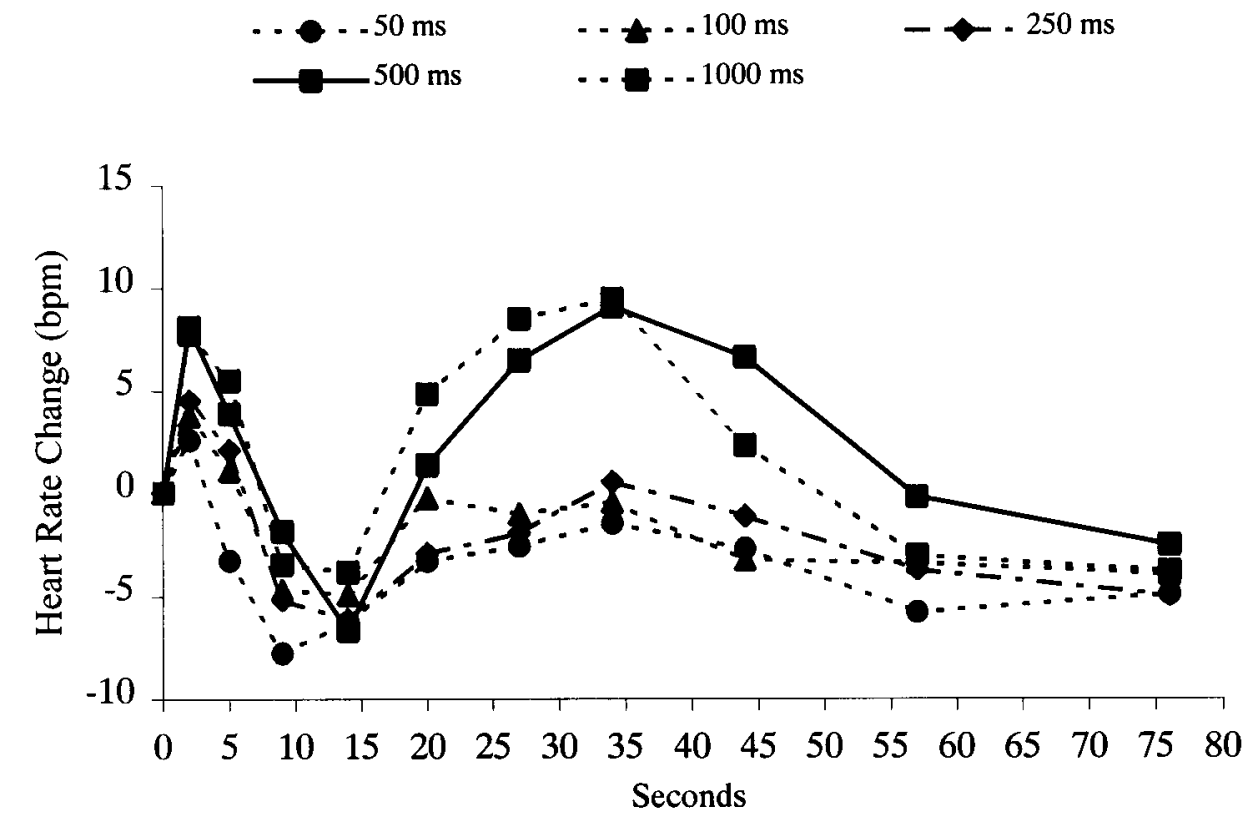

Figure 4. Cardiac Defense Response as a function of stimulus duration.
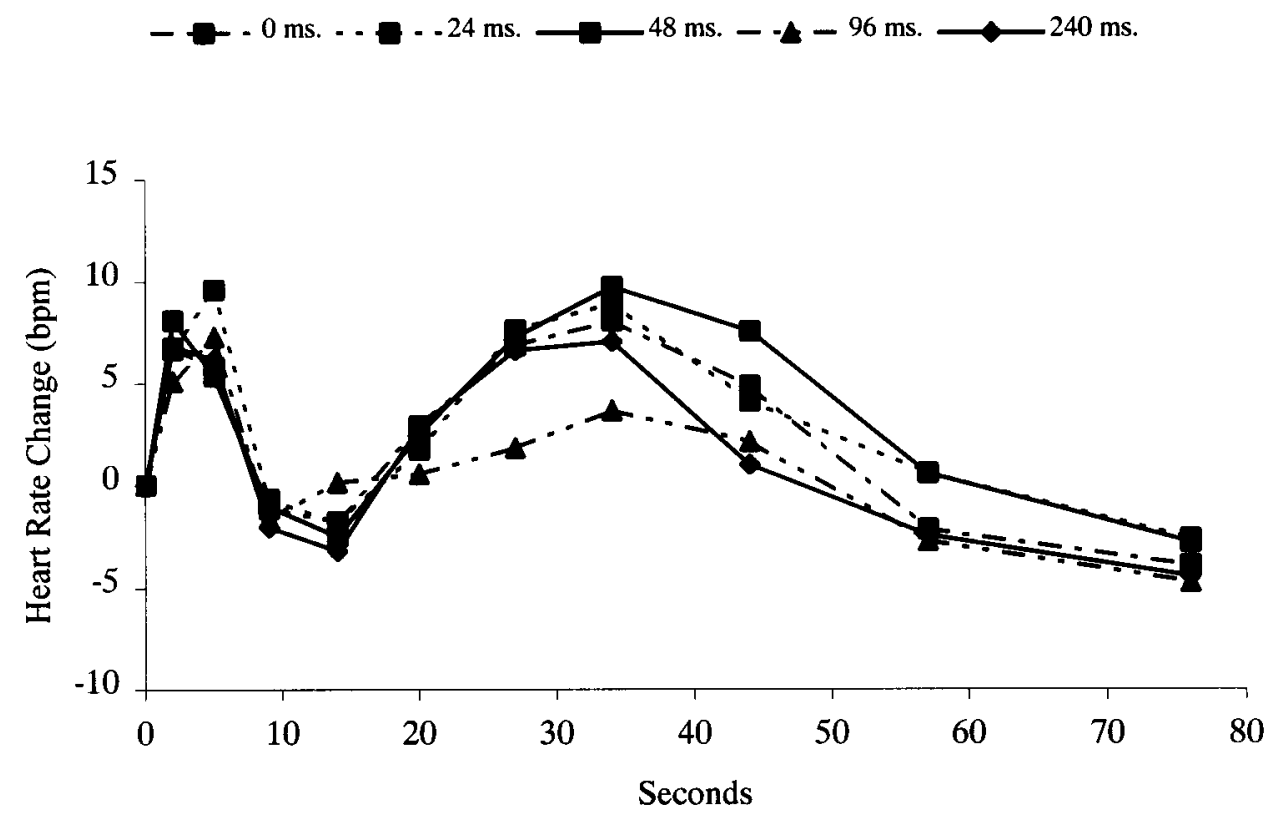

Figure 5. Cardiac Defense Response as a function of stimulus rise time.

The above data refer exclusively to the first presentation of the stimulus. In all studies, repetition of the auditory stimulus resulted in rapid habituation of the last two components of the response. The first acceleration and first deceleration also showed habituation, but the habituation trend was less pronounced. In general, these results confirm the descriptive form of the response as a pattern of heart rate changes with two accelerative and two decelerative components in alternating order, within the 80 seconds following stimulus onset. They also confirm that the whole pattern requires an eliciting stimulus of long duration (around $500 \mathrm{~ms}$ and over), but no specific rise time (even long rise times of around $240 \mathrm{~ms}$ can evoke the whole pattern). 


\section{Physiological mechanisms}

The physiological mechanisms underlying cardiac defense have been studied using indirect indexes of sympathetic_-Pulse Transit Time and Stroke Volume-and parasympathetic-Respiratory Sinus Arrhythmia and the Baroreceptor Reflex-mediation (Fernández \& Vila, 1989a; Reyes, Godoy, \& Vila. 1993; Reyes, Vila, \& García, 1994; Vila, 1995).

Pulse Transit Time - the time between the peak of the $\mathrm{R}$-wave of the Electrocardiogram and the peak of the pulse wave in the finger or in any other peripheral location-has been considered an indirect measure of ventricular contractibility and, therefore, an index of beta-adrenergic influences on the heart. A shortening of this time is interpreted as an increase in sympathetic activation. Figure 6 shows the cardiac defense response (continuous line) and the simultaneous recording of Pulse Transit Time (broken line), both expressed in z-scores. An initial decrease in sympathetic activation is followed by a sustained increase that reaches its maximum amplitude coinciding with the peak of the second acceleration. It is clear that the only coincidences occur during the second acceleration and second deceleration (see Figure 6). During the first acceleration and first deceleration, HR and PTT move in opposite directions, suggesting a non-sympathetic mediation of these early components. Similar results were obtained measuring Stroke Volume through impedance cardiography - another index of ventricular contractibility.
Also, in this study we found that the pattern of sympathetic activation disappeared under pharmacological blockade, confirming the sympathetic origin of the last two components of the response.

Respiratory Sinus Arrhythmia (RSA) - the cyclical changes in heart rate coinciding with each respiratory cycle-has been proposed as a non-invasive index of vagal control, since the arrhythmia is due exclusively to vagal inhibition during inspiration. The greater the amplitude of the arrhythmia between inspiration and expiration, the greater the vagal control on the heart rate. Analysis of the RSA during the evocation of the cardiac defense response shows a clear reduction of vagal control coinciding with the first acceleration, followed by a great increase coinciding with the first deceleration, a further decrease during the second acceleration and a final increase during the second deceleration (see Figure 7). The RSA changes move in opposite directions to the heart rate changes, suggesting a clear involvement of parasympathetic control during the defense response. Similar results were obtained when simultaneously recording heart rate and blood pressure to assess the implication of the Baroreflex in the elicitation of the response. The baroreflex is a homeostatic mechanism, mediated by the vagus, and is manifested by increases in blood pressure that are followed by decreases in heart rate, or vice versa. As in RSA, the heart rate and the systolic blood pressure moved in opposite directions during the evocation of the defense response, suggesting a clear implication of the vagus.

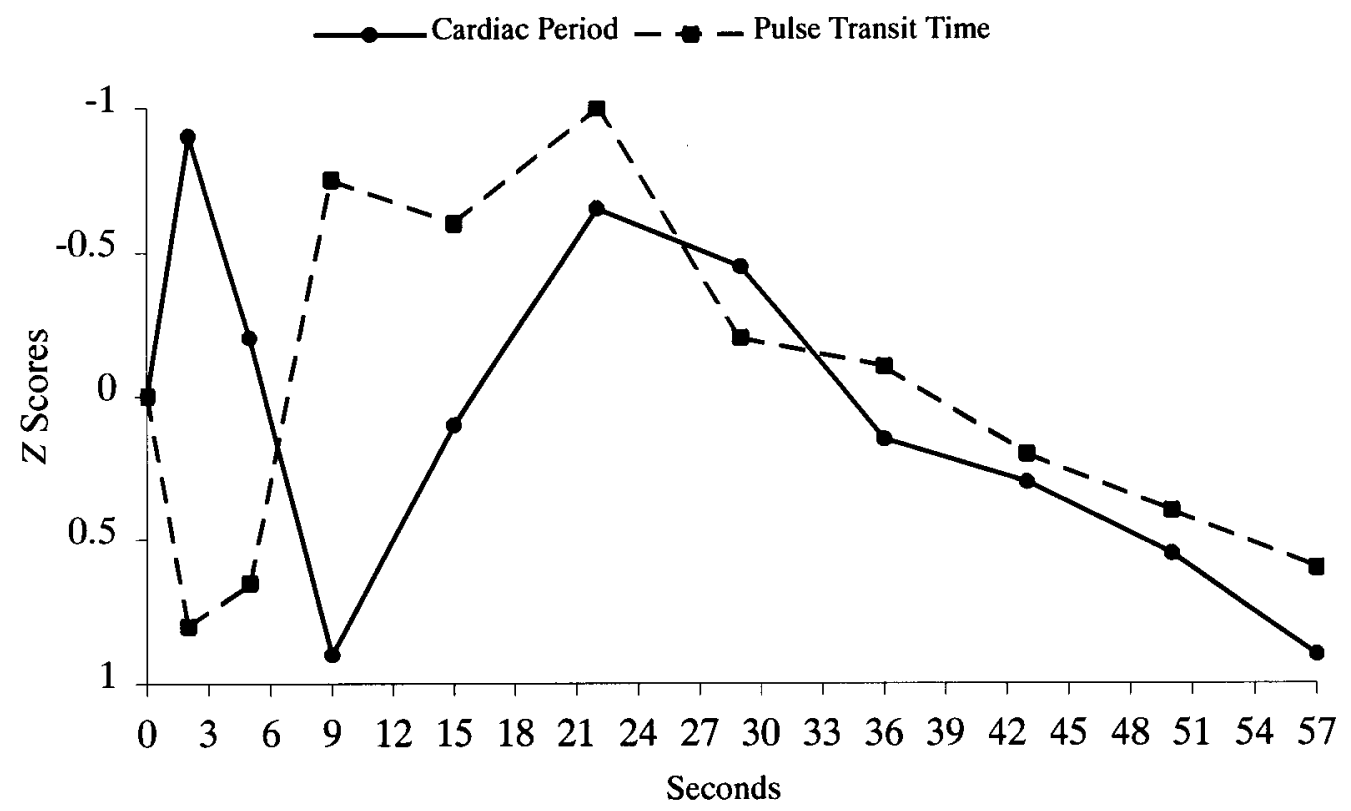

Figure 6. Simultaneous recording of the Cardiac Defense Response (in cardiac period values) and Pulse Transit Time. 
In general, these results suggest a vagal dominance during the first acceleration and first deceleration and a sympatheticvagal reciprocal interaction, with sympathetic dominance, during the second acceleration and second deceleration.

\section{Psychological mechanisms}

The classic model of cardiac defense to intense sensory stimulation assumes an attentional interpretation of the heart rate changes: The organism protects itself against the aversive stimulus by reducing external sensory processing (attentional rejection). In contrast, the motivational approach to cardiac defense-based on emotionally or cognitively challenging tasks-assumes an energetic interpretation of the observed heart rate changes: The organism protects itself by preparing for active defense (fight or flight). These two alternative interpretations have been systematically examined in a series of studies seeking to identify attentional and emotional factors affecting the heart rate response to intense auditory stimulation.

\section{Cognitive involvement: Attention}

According to the classic model, cardiac defense should be accompanied by a decrease in sensory processing as a form of attentional rejection of the stimulus. Therefore, cardiac defense should correlate positively with indexes of sensory rejection (internal attention) and negatively with indexes of sensory intake (external attention), to use Lacey's terminology. However, our studies consistently confirm the opposite prediction: a clear positive relationship of cardiac defense with attentional processes of sensory intake (increase in external attention).

In one of these studies we superimposed the evocation of the defense response on a secondary task in which we manipulated the direction of the attentional mechanism: external versus internal. Participants had either to press a telegraph key tracking an external light that came on and went off every half second during the period in which the cardiac response was evoked (external attention), or to press the same telegraph key in coincidence not with the light but with the perception of their heart beats (internal attention). Figure 8 shows the results of this study (Vila, Pérez, Fernández, Pegalajar, \& Sánchez, 1997). There is a clear potentiation of the second accelerative component of the response when participants were performing the externallydirected attention task (intake). This modulatory effect of external attention on cardiac defense is also consistent with a significant relationship found in a previous study (Fernández \& Vila, 1989b) between the presence of the second accelerative component and greater cardiac reactivity in tasks of simple reaction time (intake), but not in tasks of mental arithmetic (rejection).

Subsequent studies have tried to answer the question of whether this potentiation was dependent on the direction of attention during the task or on the extent of attention, as represented by workload and demand, and as suggested by Turpin (1986). Figure 9 shows the results of a study in which we manipulated cognitive demand by introducing a different internally-directed task-Sternberg's memory search task at two levels of task difficulty (easy being to memorize only two letters, and difficult being to memorize

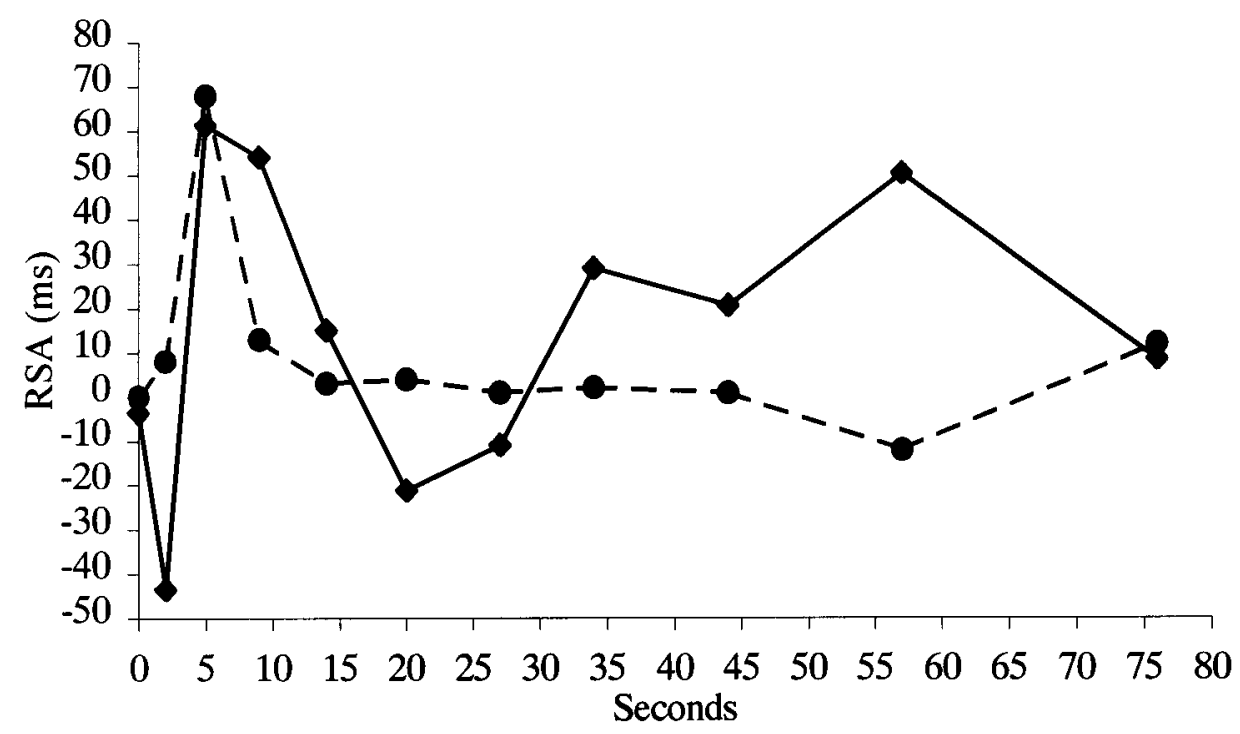

Figure 7. Respiratory Sinus Arrhythmia recording during the evocation of the Cardiac Defense Response in participants who did evoke the second acceleration (continuous line) and participants who did not evoke the second acceleration (broken line). 


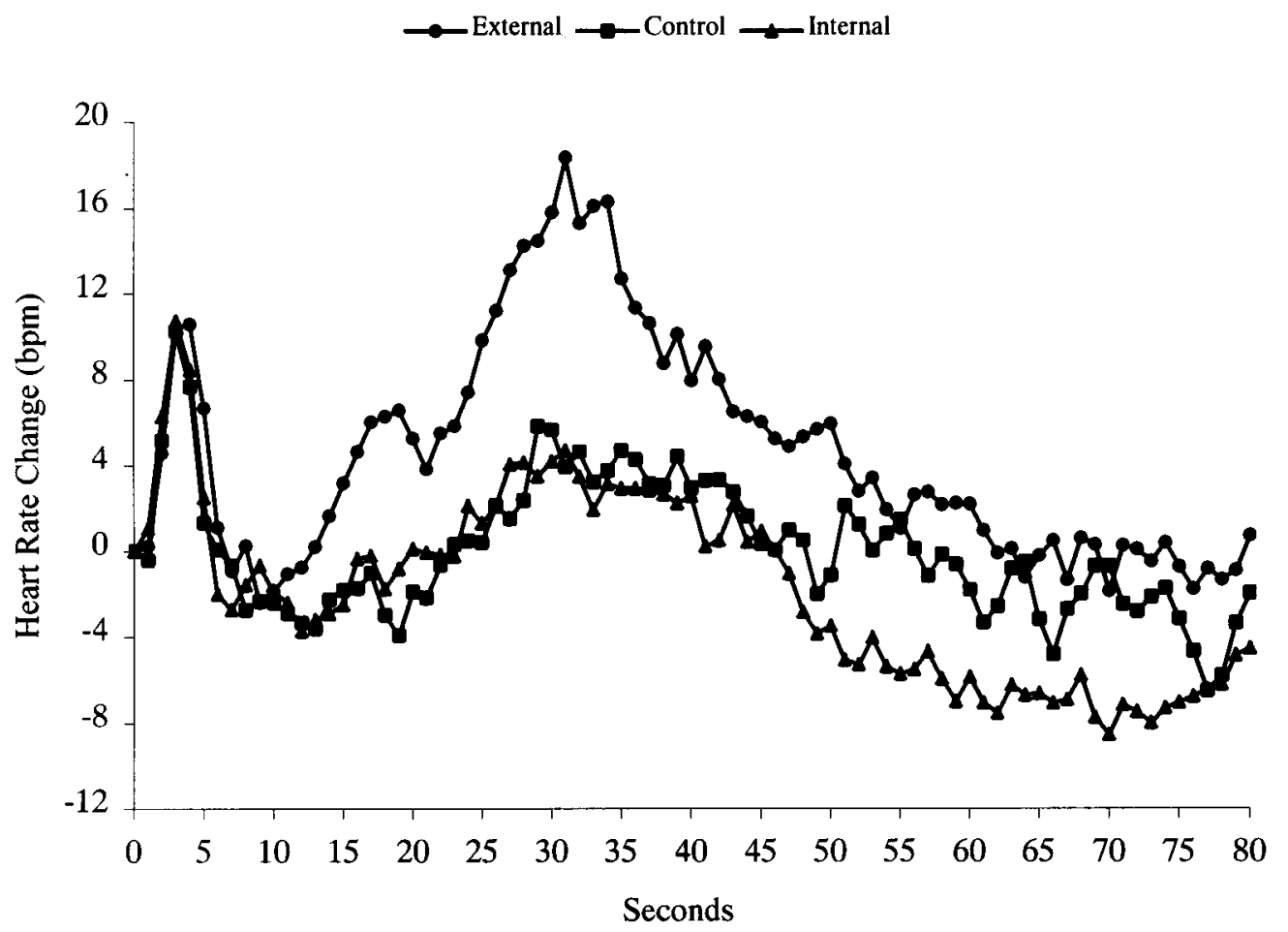

Figure 8. Attentional modulation of the Cardiac Defense Response by external attention versus internal attention and control.

seven letters)_, in addition to the control group and the tracking group of the previous study (Pérez, Fernández, Vila, \& Turpin, 2000). Results again show potentiation of cardiac defense to the first presentation of the acoustic stimulus only in the tracking (external attention) task.

A final study also manipulated the direction of attention (external versus internal) by comparing two parallel cognitive tasks: Sternberg's memory search task (internal) versus Sternberg's visual search task (external). In the memory task, participants had to recognize a letter as belonging or not to a previously-memorized set of letters. In the visual task, participants had to detect a letter within a currentlypresented set of letters. In addition, two levels of task difficulty and two levels of task-defense response contingency were manipulated. Results (Ramírez, Pérez, Sánchez, \& Vila, 1999) again show a potentiation of the second accelerative component of the response in the visual condition (external attention). There was also a main effect of contingency, whereas task difficulty did not affect the response at all (Figure 10). The potentiation of cardiac defense by attentional processes of sensory intake is contrary to the classic model- "shut down sensory processing", "rejection of the stimulus"-but is consistent with a naturalistic view of defense when it occurs in important settings for the survival of the organism, as we shall discuss later.

\section{Motivational involvement: Emotion}

As regards motivational involvement, we have used different procedures to study the response under various emotional states (García-León, Vila, Reyes, \& Pérez, 2002; Ruiz-Padial, Sánchez, Thayer, \& Vila, 2002; Sánchez, RuizPadial, Pérez, Fernández, Cobos, \& Vila, 2002). In our latest studies we have closely followed Peter Lang's paradigm of emotional modulation of the eye blink startle response during the presentation of affective pictures. The IAPS (International Affective Picture System) is an instrument for studying emotion in laboratory conditions developed by Lang's group at the University of Florida. It consists of a large set of pictures evaluated in two major emotional dimensions: valence (pleasant-unpleasant) and arousal (relaxing-activating). The startle response is a motor response elicited by abrupt and brief intense stimuli such as white noise of $100 \mathrm{~dB}$ and of $50 \mathrm{~ms}$ duration, and with instantaneous rise time. The first component of startle is an eye blink that can be measured by recording the electromyogram of the orbicularis oculi. One of the major results obtained, using Lang's paradigm of superposing acoustic probes on picture viewing, is the potentiation of the eye blink response when participants are viewing unpleasant pictures and the inhibition of the response when they are viewing pleasant pictures. 

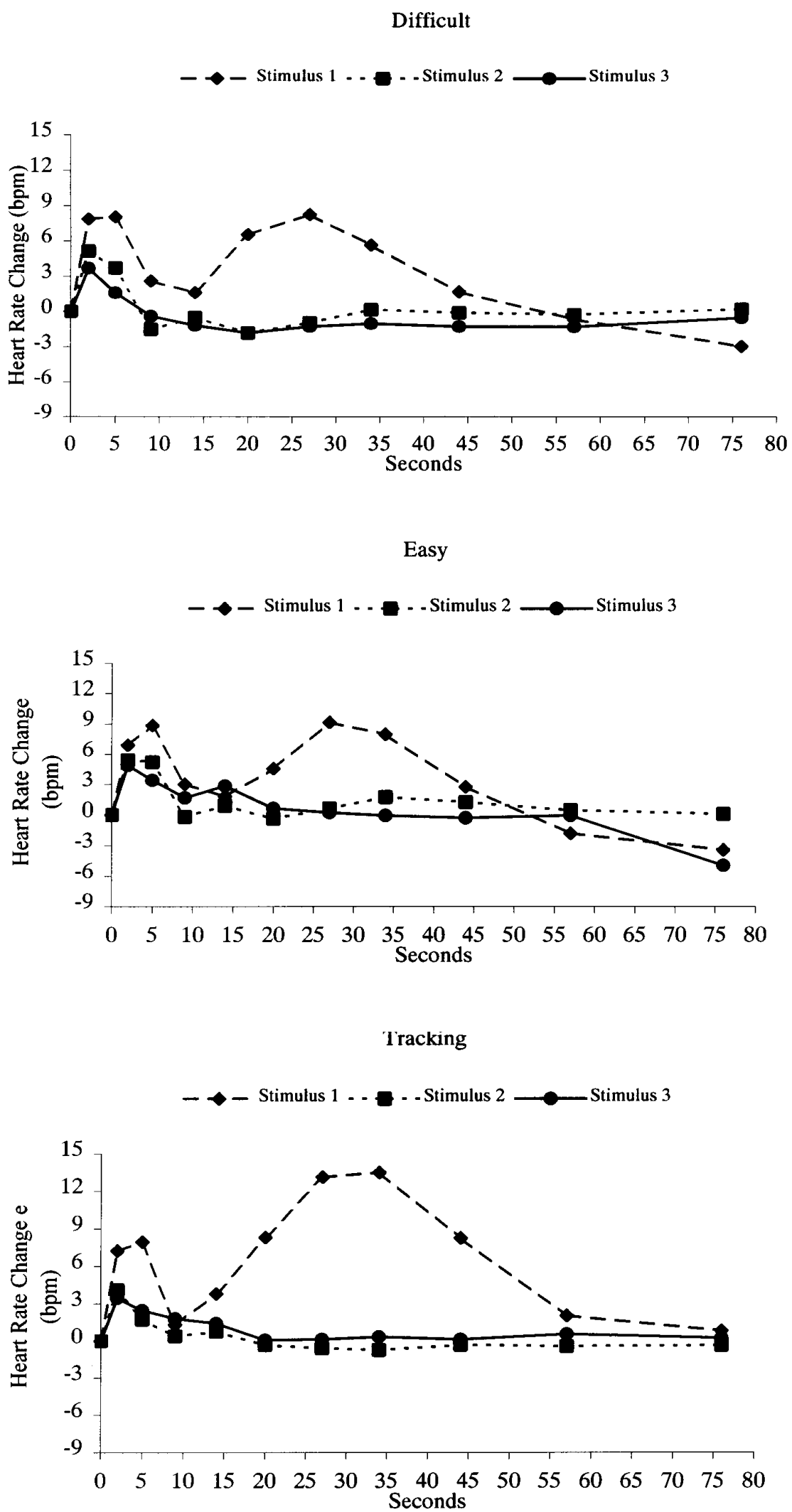

Figure 9. Attentional modulation of the Cardiac Defense Response by external attention (bottom) versus internal attention (top and middle). Stimuli 1, 2, and 3 are the three presentations of the acoustic stimulus. 
Non-Contingent Memory

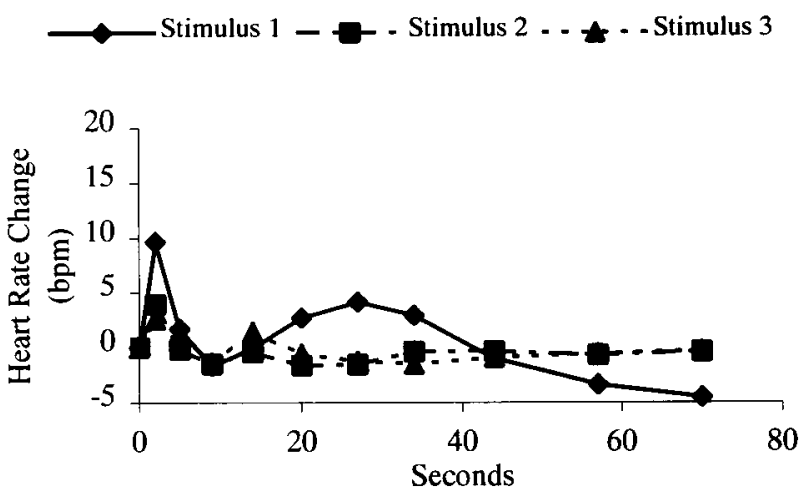

Non-Contingent Visual

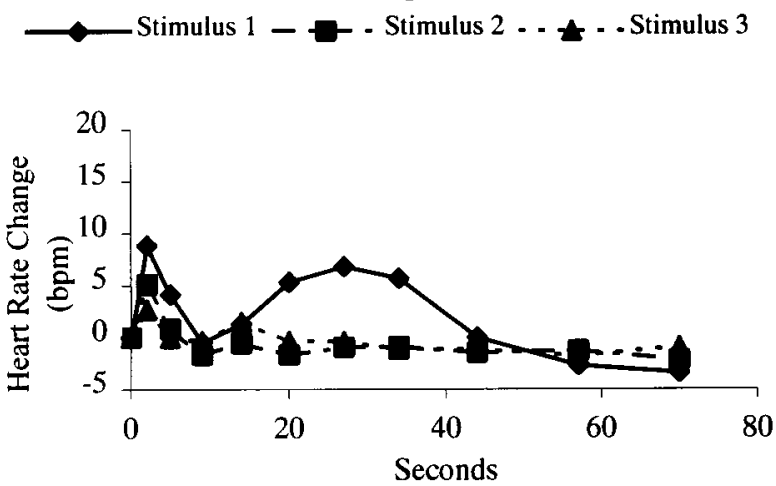

Contingent Memory

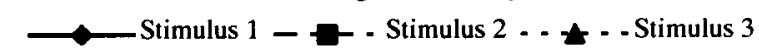

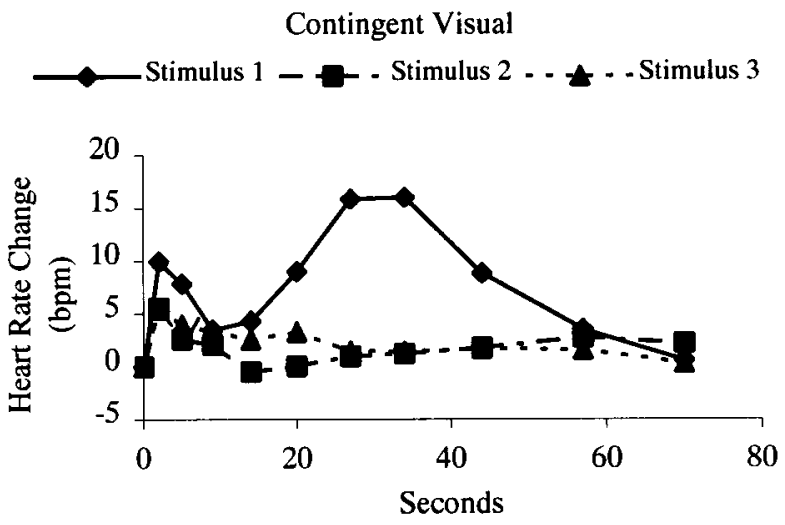

Figure 10. Attentional modulation of the Cardiac Defense Response by visual attention (bottom figures) versus memory (top figures), and by contingency (right figures) versus non-contingency (left figures). Stimuli 1, 2, and 3 are the three presentations of the acoustic stimulus.

Lang and colleagues (Bradley, 2000; Lang, 1995; Lang, Bradley, \& Cuthbert, 1997) have designed a theoretical model to explain this phenomenon: the motivational priming theory. According to this model, defensive reflexes, such as startle, are potentiated when there is congruence between the emotional state of the subject-negative-and the motivational system underlying the reflex-aversive. In contrast, inhibition is expected to occur if there is incongruence between the emotional state-positive-and the motivational system underlying the reflex-aversive.

In our studies, we have examined the effect of viewing unpleasant and phobic slide pictures on both cardiac defense and eye blink startle by using acoustic stimuli of long duration (500 or $1000 \mathrm{~ms})$ and short rise time (instantaneous), in order to allow evocation of both reflexes. In the first study we used three pleasant, three neutral and three unpleasant pictures selected from the Spanish IAPS (Moltó et al., 1999). The order of presentation was balanced using a Latin square design. The acoustic stimulus was presented around the mid-point of the six-second viewing time period for each picture. Results not only show a clear potentiation of cardiac defense to the first noise when participants were viewing the unpleasant picture, but also a profound modification of the pattern of the response: The first deceleration disappeared and the two accelerations moved closer together (see Figure 11, top). This effect was only observed in the first trial. As regards the results concerning eye blink magnitude, these replicated similar findings by Lang and colleagues (see Figure 11, bottom). The topographical change in the heart rate response, showing a single large accelerative component, may help to understand contradictory reports on the description of cardiac defense. The full, complex pattern of accelerative and decelerative components is only observed when the aversive stimulus is presented unexpectedly, without anticipatory or priming stimuli. When the aversive stimulus is preceded by signaled or priming stimuli, the first and second accelerations change into a single larger acceleration. 

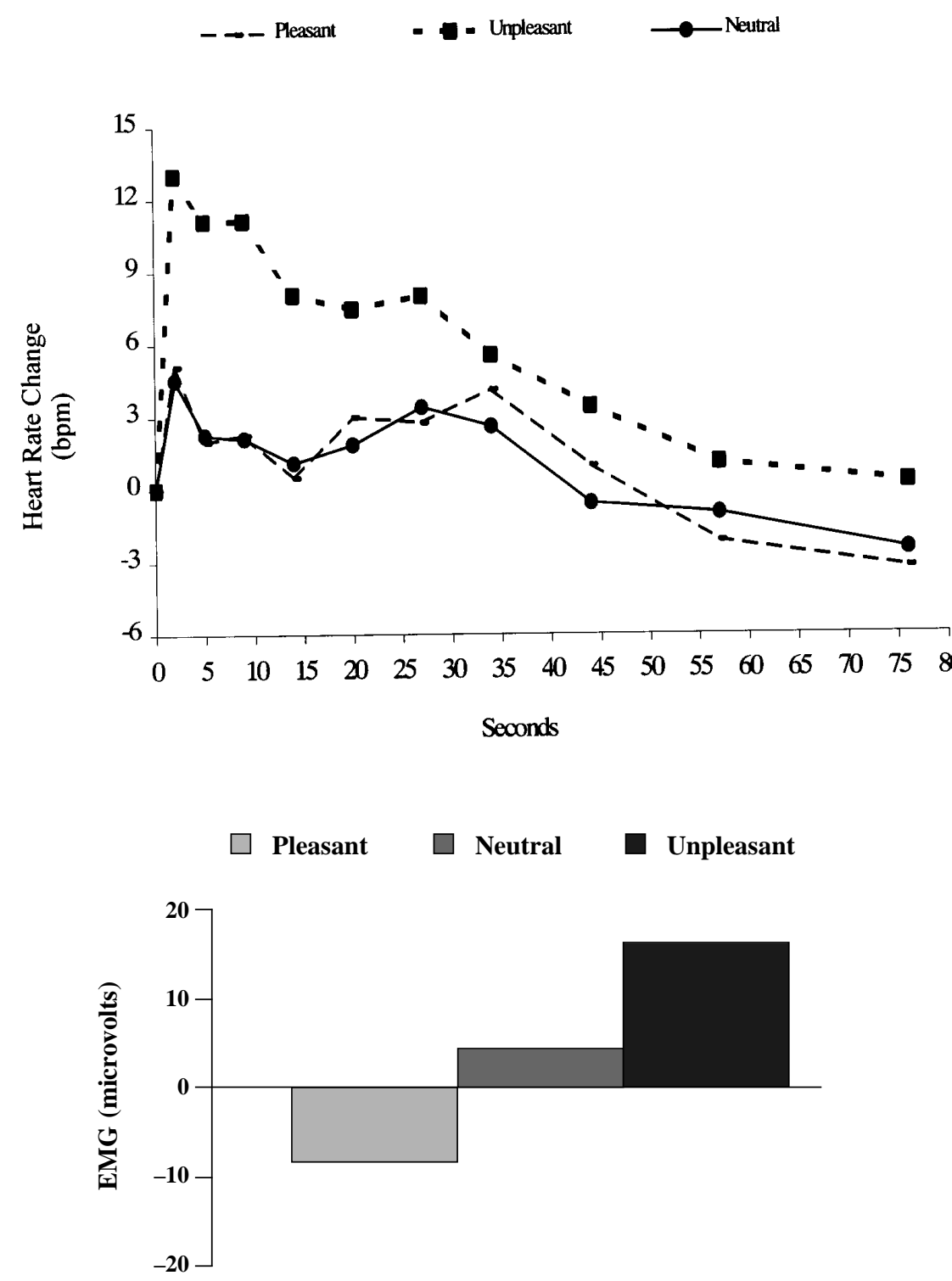

Figure 11. Emotional modulation of the Cardiac Defense Response (top) and the Eye Blink Startle Response (bottom) by simultaneously viewing unpleasant, neutral, and pleasant pictures.

A second study examined the effect on cardiac defense and eye blink startle of viewing phobic and non-phobic pictures. We expected an even greater potentiation of cardiac defense under these conditions. Three groups of participants were examined: (a) a group of animal phobic but not blood phobic participants; (b) a group of blood phobic but not animal phobic participants; and (c) a group of participants with no fear of animals or blood. All participants had just two defense acoustic trials: one while viewing a picture of an animal and the other while viewing a picture of blood, in counterbalanced order. Results again showed a clear potentiation of the accelerative components of the response when phobic participants were viewing their phobic object, as compared to their non-phobic object, or to both in nonphobic participants (Figure 12). Also evident in this graph is the topographical change in the form of the cardiac response. As regards eye blink startle, our results again replicate those of Lang and colleagues (Figure 13).

A final series of studies (Ruiz-Padial, 2003) has examined this priming effect, but under non-conscious presentation of the phobic pictures, by using a backward masking procedure similar to that employed by Öhman and colleagues in their studies on pre-attentive processing of phobic stimuli (Öhman $\&$ Soares, 1994). Since they have always used the skin conductance response as an index of the unconscious processing of threat, the confirmation of similar effects using 

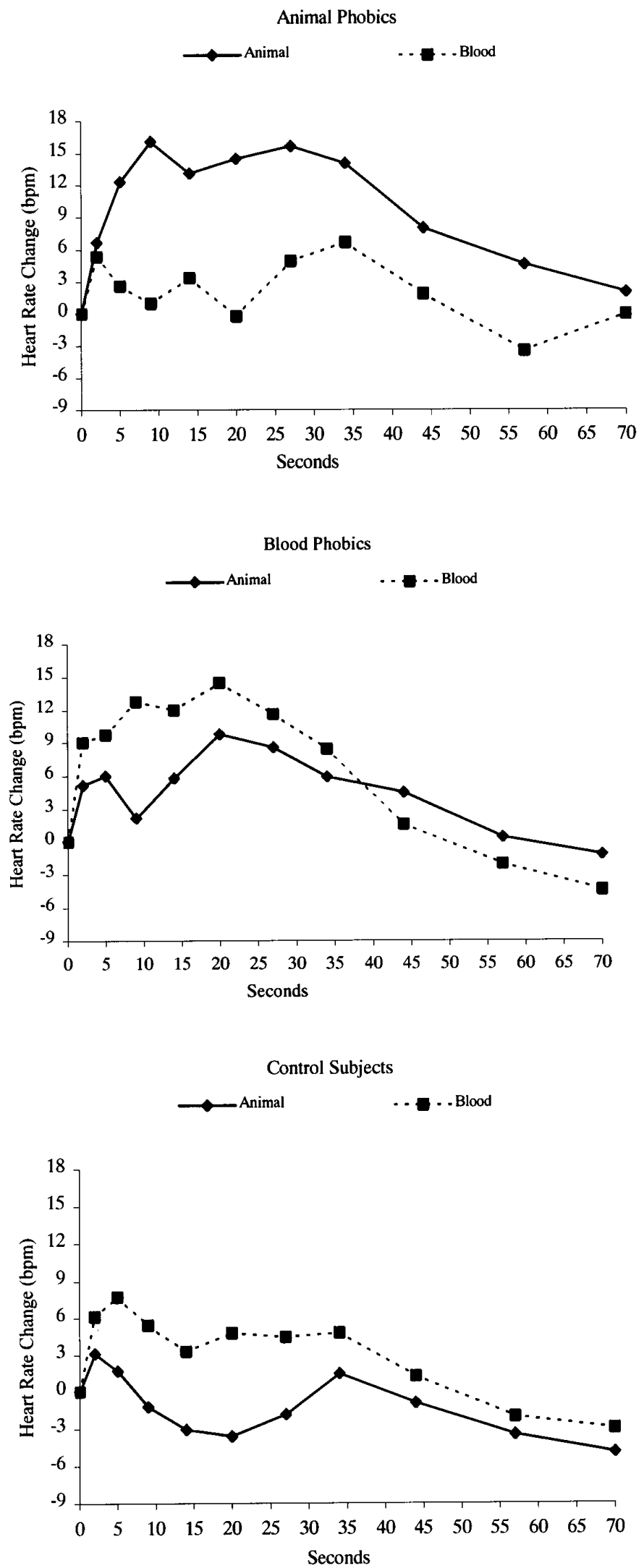

Figure 12. Emotional modulation of the Cardiac Defense Response by simultaneously viewing phobic and non-phobic pictures. 


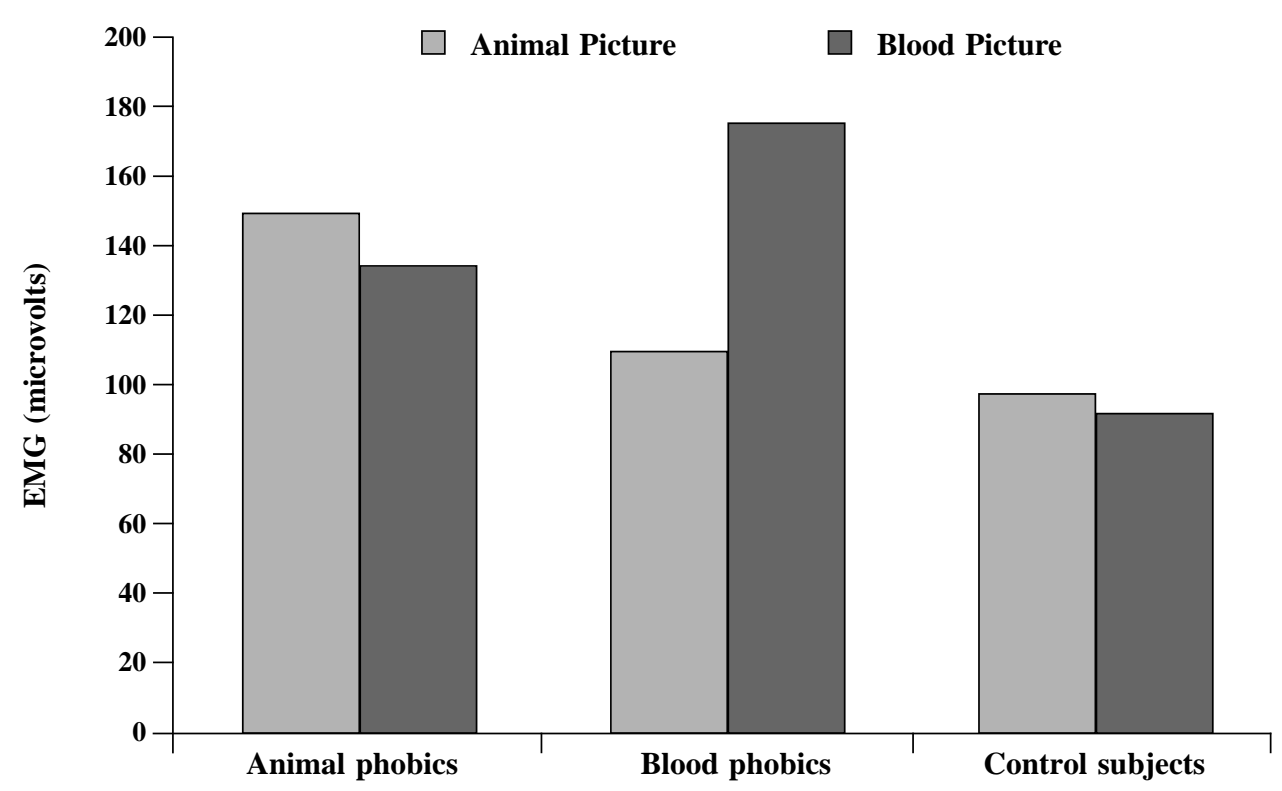

Figure 13. Emotional modulation of the Eye Blink Startle Response by simultaneously viewing phobic and non-phobic pictures.

Conscious Order 1

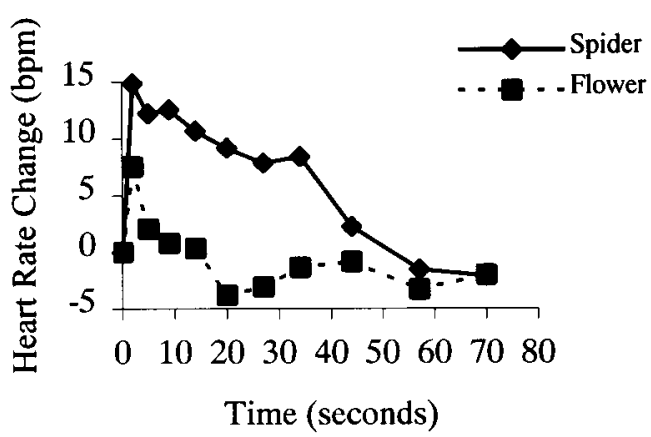

Non-Conscious Order 1

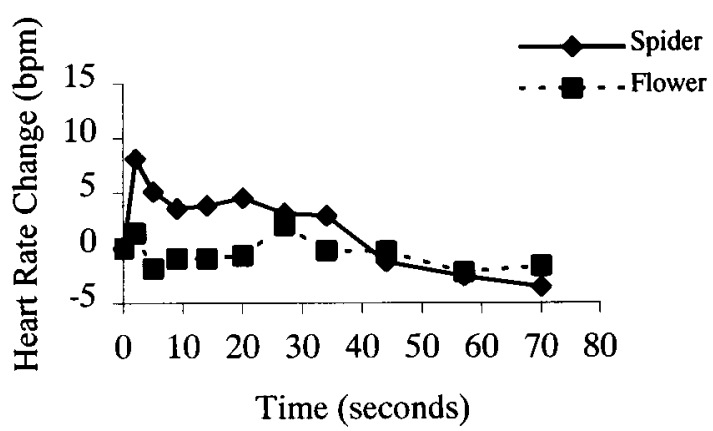

Conscious Order 2

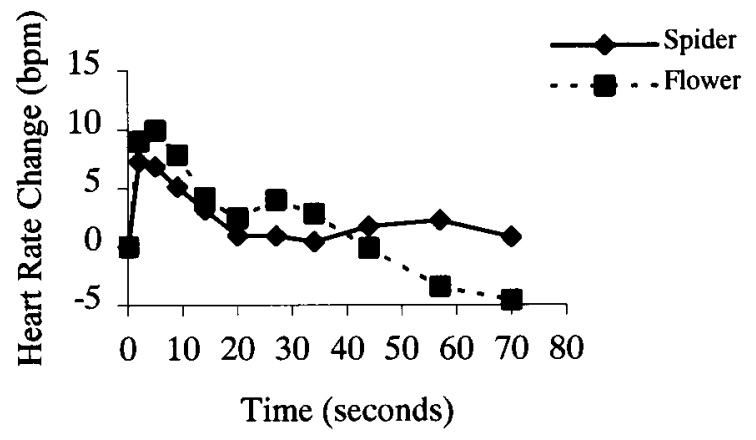

Non-Conscious Order 2

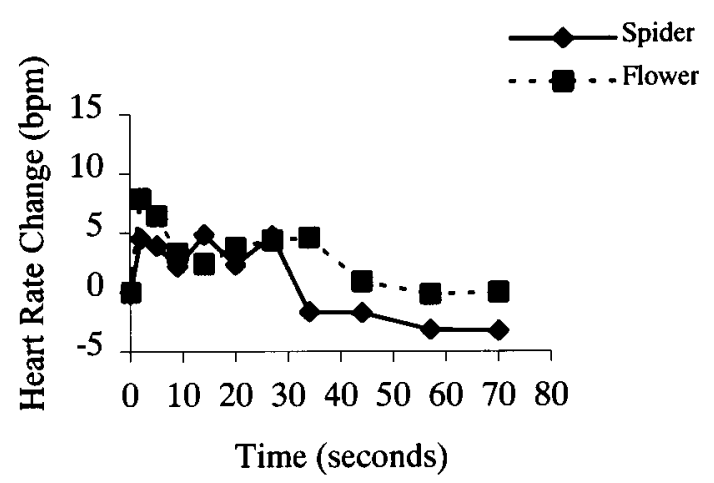

Figure 14. Non-conscious emotional modulation of the Cardiac Defense Response by simultaneously viewing phobic and non-phobic pictures under effective backward masking (Order 1 = spider first, flower second; Order 2 = flower first, spider second). 
Conscious Group

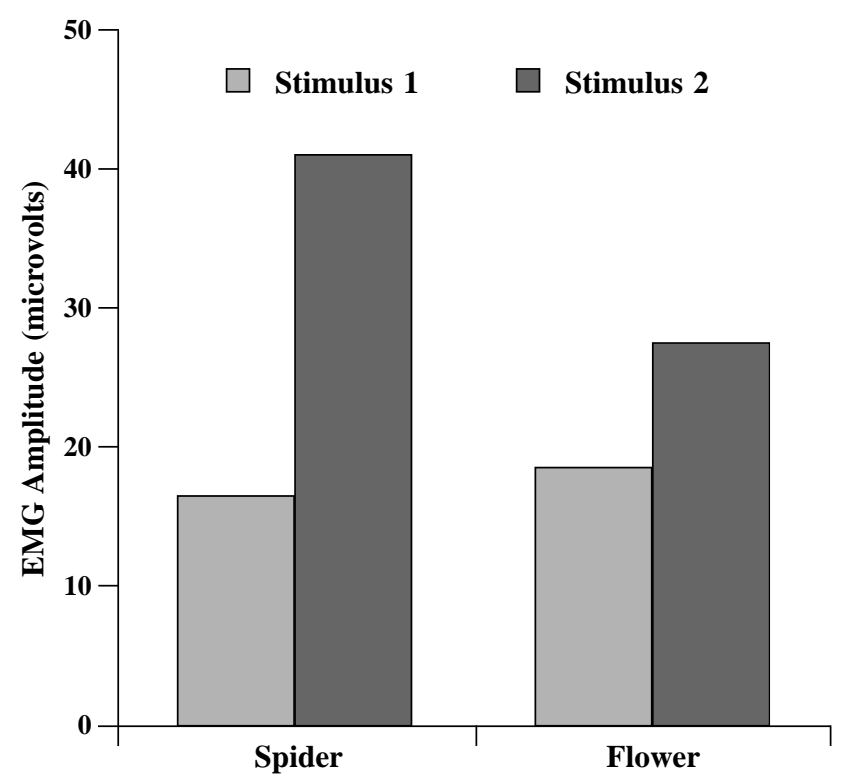

Non-Conscious Group

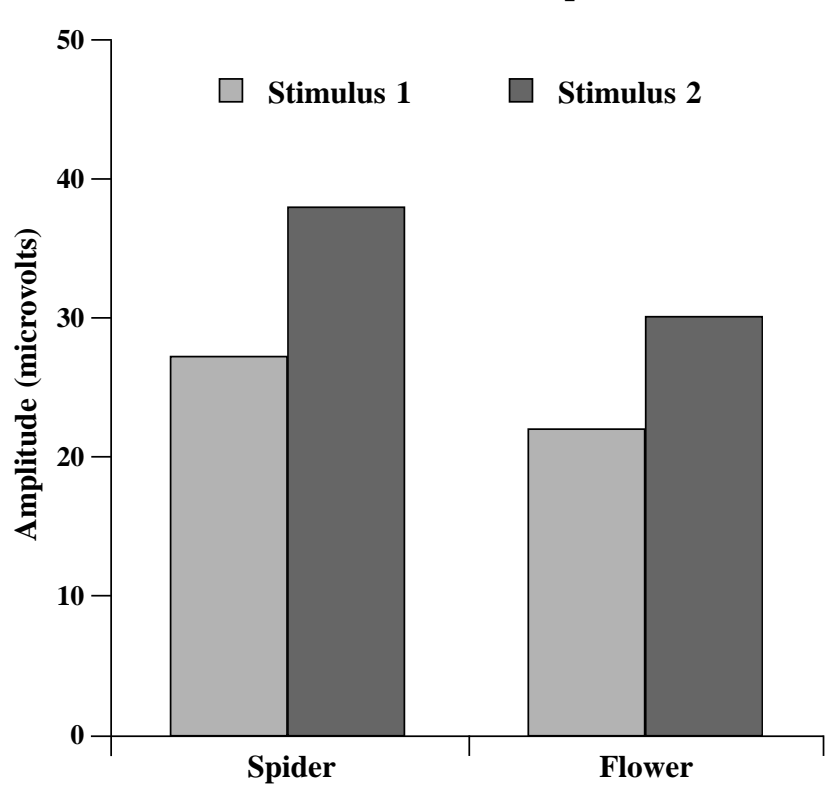

Figure 15. Non-conscious emotional modulation of the Eye Blink Startle Response by simultaneously viewing phobic and non-phobic pictures under effective backward masking.

defensive reflexes, such as motor startle and cardiac defense, would provide further support for Öhman's theory of preattentional fear processing. Figure 14 shows the results of a study in which a group of spider phobic participants had two consecutive defense acoustic trials-one while viewing a picture of a spider and the other while viewing a picture of a flower, in counterbalanced order-, either under non-effective masking conditions-conscious group-or under effective masking conditions-non-conscious group. As can be seen in Figure 14, both conscious and nonconscious groups showed potentiation of the cardiac defense response when viewing the phobic picture, as compared to the non-phobic picture, reproducing the same response pattern as in previous studies (the effect being more evident when the phobic picture was presented first and the non-phobic picture second). Furthermore, eye blink startle showed similar potentiation, both under conscious and non-conscious conditions, although in this case the effect was more evident when the phobic picture was presented second and the nonphobic picture first (Figure 15).

\section{Discussion}

In contrast to the classic model, cardiac defense to intense stimulation is characterized, at least in humans, by a complex sequence of heart rate changes with both accelerative and decelerative components, with both parasympathetic and sympathetic influences, and with both attentional and emotional significance. The implications of this new conceptualization are various.
Firstly, this description emphasizes the dynamic character of the defense response - obvious in natural settings — and the simultaneous involvement of different physiological and psychological mechanisms. In natural settings, such as those involving the imminence of a predator, the defense reaction is not a single response that could be conceptualized as cognitive versus motivational, or vice versa. Rather, the defense reaction follows a dynamic sequential process with initial phases in which aversively-motivated attentional factors, aimed at detection and analysis of the potential danger, predominate; if the process continues, there follow phases with a predominance of aversively-motivated protective actions, aimed at active defense, such as fight or flight. Depending on the spatial and temporal proximity of the predator, different components of the defense reaction may take place successively, as has been emphasized by animal researchers (Blanchard \& Blanchard, 1989; Fanselow, 1994; Fendt \& Fanselow, 1999; Lang, Bradley, \& Cuthbert, 1997; Lang, Davis, \& Öhman, 2002). Supporting this view, the topographical change in the cardiac defense response, observed when the aversive stimulus is primed by preceding unpleasant or phobic pictures, suggests that the attentional factors might have already been triggered by the preceding stimuli, and that the preparation of protective actions is temporally advanced to better match successful adaptation. Thus, the pattern of heart rate changes observed in response to unexpected intense aversive stimuli, with accelerative and decelerative components, seems to reflect the transition from attention (first acceleration and first deceleration) to action (second acceleration and second deceleration), a sequential process that becomes altered when the eliciting stimulus is primed by preceding threatening signals. 
Secondly, the new approach to cardiac defense emphasizes the brain mechanisms underlying protective actions. The structural foundation of the defense reactions is in the brain's aversive motive system. Neuroscientists have traced the chain of neural activation in the brain, starting from the sensory input, proceeding through the subcortical and cortical connecting structures, and finishing in the autonomic and motor effectors (Davis, 1996; Lane \& Nadel, 2000; LeDoux, 1996; Thayer \& Siegle, 2002). Although the exact pathways are still in part unknown, a critical structure in this circuit is the amygdala, a subcortical center that receives inputs from the sensory thalamus and various cortical structures. Downstream from the amygdala, the defense circuit branches into different structures, controlling separate forms of defense. As Lang, Davis, and Öhman (2002) have suggested, this hierarchical organization, together with the learned plasticity in the anatomy and functioning of the brain's structures, provides considerable variety in the pattern of defensive output. Depending on the situational context and on the weight of the local pathways within the circuit, the aversively-motivated responses can be escape or avoidance, aggressive behavior, hormonal and autonomic responses, or the augmentation of protective reflexes. Most of the research supporting this model has been conducted in animals and using defensive reactions different from cardiac defense-mainly freezing and motor startle. Our results give further support to this neural model, in particular as regards the potentiation of the response by viewing unpleasant and phobic pictures, since they suggest that the same modulatory mechanism-activation of the central nucleus of the amygdala-also applies to autonomic reflexes such as cardiac defense.

Thirdly, in spite of the similarities among defensive reactions, eye blink startle and cardiac defense also show important differences. Both can be elicited by intense acoustic stimulation, but the parametric characteristics of the eliciting stimuli are different. The whole pattern of the cardiac defense response requires an eliciting stimulus of long duration (around $500 \mathrm{~ms}$ and over) but no specific rise time (even long rise times of around $240 \mathrm{~ms}$ can evoke the whole pattern). In contrast, motor startle can be elicited with short and long stimulus durations (50 ms and over), but requires very short rise times (less than $24 \mathrm{~ms}$ ). Therefore, by manipulating the duration and rise time of the stimulus we can evoke (a) both cardiac defense and motor startle (using stimulus of long duration and short rise time); (b) cardiac defense alone (using stimulus of long duration and long rise time); and (c) motor startle alone (using stimulus of short duration and short rise time). When the two reflexes are recorded simultaneously using acoustic stimuli of long duration and short rise time, as in the studies reported above, differences between them also appear with regard to habituation of the response: Whereas cardiac defense habituates rapidly, motor startle habituates slowly or even shows sensitization during the first few trials. In addition to suggesting specific primary circuits for each reflex, these results advise the use of different methodological designs to study the two reflexes separately: between-group designs for cardiac defense and within-group designs for motor startle.

Fourthly, the involvement of attentional factors in defense-contrary to the traditional view of decrement in sensory processing-also has important implications for understanding the detection of threat stimuli and fear processing. Early detection of threat can be critical to survival. Öhman and colleagues (Öhman, 2000; Öhman \& Mineka, 2001) have conducted an extensive series of studies on pre-attentional processing of fear stimuli using the backward masking technique, in combination with the skin conductance response, to show that fear-relevant stimuli (pictures of snakes, spiders, and fear-angry faces), as compared to fear-irrelevant stimuli (pictures of flowers, mushrooms, and neutral-happy faces), can be pre-attentively processed without reaching consciousness. According to these authors, the pre-attentive activation of defensive reactions, before conscious appraisal of the stimulus, would explain the sense of uncontrollability and overestimation of danger that phobic people experience. In Öhman's studies, no specific measure of defense, such as eye blink startle or cardiac defense, was taken. The skin conductance response does not differentiate between orienting and defense and, according to the classic model based on Sokolov (1963), the attentional function of defense is opposite to that of orienting. Thus, it is difficult to conclude from Öhman's studies whether the data on masked processing of aversive stimuli are indicative of orienting or defense, or both. Our finding of a potentiated cardiac defense and eye blink startle when the masked phobic stimulus was presented suggests that the nature of the response was indeed defensive. Therefore, the attentional factor involved in the processing of masked phobic stimuli should be interpreted as part of the defensive reaction itself, rather than as part of an opposite orienting response. This gives further support to the idea of both attentional and emotional involvement in defense.

Finally, the new approach to defense also has implications for the stress concept and stress-related illnesses. The traditional approaches did not emphasize the dynamic character of the defense response-obvious in natural settings-, nor the simultaneous involvement of different psychological processes - attentional and motivational. The new approach fits better with the prevalent model of stress in health-related disciplines: the cognitive-transactional model (Lazarus \& Folkman, 1984). The continuous dynamic interaction between the situation and the person, leading to activation or de-activation of the stress response, is the main feature of the transactional model. Furthermore, the new approach to defense can help to better define the specific nature of stress, differentiating it from other, related concepts such as anxiety, fear, or arousal. Based on the new approach, stress can be defined as the sustained activation of the brain's defense motivational system. A state of maintained activation of this system implies a variety of specific defense responses 
being continuously elicited, including neural and moodrelated responses that correlate with poor physical and mental health: sustained increases in heart rate and blood pressure, and sustained decreases in respiratory sinus arrhythmia and cardiac variability.

The data presented here on cardiac defense constitute an example of the potential use of peripheral measures to unravel the complex brain mechanisms controlling adaptive behavior. The utility of heart rate to index important aspects of brain physiology and behavior is making cardiac psychophysiology one of the most valuable tools for researchers interested in basic science and health. However, our present knowledge on brain mechanisms involved in cardiac and emotional regulation is still limited. Moreover, the studies reported here are not without methodological shortcomings. Future research will need to confirm and extend the present results, as well as to advance knowledge on the neural networks through which the brain controls visceromotor responses that are critical for adaptability and health.

\section{References}

Belkic, K. (1986). Light stress and the cardiovascular system: The glare pressor test. Ergonomics, 29, 563-568.

Blanchard, R. J., \& Blanchard, D. C. (1989). Attack and defense in rodents as ethoexperimental models for the study of emotion. Progress in Neuro-Psychopharmacology and Biological Psychiatry, 13, 3-14.

Bond, D. D. (1943). Sympathetic and vagal interaction in emotional responses of the heart rate. American Journal of Physiology, $138,468-478$

Bradley, M. M. (2000). Emotion and motivation. In J. T. Cacioppo, L. G. Tassinary, \& G. G. Berntson (Eds.), Handbook of psychophysiology (pp. 602-642). Cambridge, UK: Cambridge University Press.

Cannon, W. B. (1929). Bodily changes in pain, hunger, fear and rage. An account of researches into the function of emotional excitement. New York: Appleton Century Crofts.

Coles, M. G. H., Jennings, J. R., \& Stern, J. A. (Eds.) (1984). Psychophysiological perspectives: Festschrift for Beatrice and John Lacey. New York: Reinhold.

Davis, M. (1996). Differential roles of the amygdala and bed nucleus of the stria terminalis in conditioned fear and startle enhanced by corticotropin-releasing hormone. In T. Ono, B. L. McNaughton, S. Molotchnikoff, E. T. Rolls, \& H. Nishijo (Eds.), Perception, memory and emotion: Frontiers in neuroscience (pp. 525-548). Oxford: Elsevier.

Eves, F. F., \& Gruzelier, J. M. (1984). Individual differences in the cardiac response to high intensity auditory stimulation. Psychophysiology, 21, 342-352.

Eves, F. F., \& Gruzelier, J. M. (1985). Individual differences in the cardiac response to novel stimuli. In J. F. Orlebeke, G. Mulder, \& L. J. P. Van Doornen (Eds.), Psychophysiology of cardiovascular control (pp. 637-648). New York: Plenum Press.
Fanselow, M. S. (1994). Neural organization of the defense behavior system responsible for fear. Psychonomic Bulletin and Review, $1,429-438$.

Fendt, M., \& Fanselow, M. S. (1999). The neuroanatomical and neurochemical basis of conditioned fear. Neuroscience and Biobehavioral Reviews, 23, 743-760.

Fernández, M. C., \& Vila, J. (1989a). Sympathetic-parasympathetic mediation of the cardiac defense response in humans. Biological Psychology, 28, 123-133.

Fernández, M. C., \& Vila, J. (1989b). Cognitive versus motivational significance of the cardiac response to intense auditory stimulation. International Journal of Psychophysiology, 8, 4959.

García León, A. (1997). Efectos de la hostilidad/ira sobre la reactividad cardiovascular en paradigmas tónicos y fásicos (La respuesta cardiaca de defensa). Unpublished doctoral dissertation, University of Granada, Spain.

García-León, A., Vila, J., Reyes del Paso, G., \& Pérez, M. N. (2002). Efectos de la frustración y el hostigamiento en la modulación emocional de la respuesta cardiaca de defensa. Psicothema, 14, 450-455.

Graham, F. K. (1979). Distinguishing among orienting, defense and startle reflexes. In H. D. Kimmel, E. H. van Olst, \& F. J. Orlebeke (Eds.), The orienting reflex in humans (pp. 137167). Hillsdale, NJ: Erlbaum.

Hare, R. D. (1973). Orienting and defensive responses to visual stimuli. Psychophysiology, 10, 453-464.

Klorman, R., Weissbert, R. P., \& Wiessenfeld, A. R. (1977). Individual differences in fear and autonomic reactions to affective stimulation. Psychophysiology, 14, 45-51.

Kryter, K. D. (1970). The effect of noise on man. London: Academic Press.

Lacey, B. C., \& Lacey, J. I. (1974). Studies of heart rate and other bodily processes in sensoriomotor behavior. In P. A. Obrist, A. H. Black, J. Brener, \& L. V. DiCara (Eds.), Cardiovascular psychophysiology: Current issues in response mechanisms, biofeedback and methodology (pp. 358-564). Chicago, IL: Aldine-Atherton.

Lacey, J. I., \& Lacey, B. C. (1970). Some autonomic-central nervous system interrelationships. In P. Black (Ed.), Physiological correlates of emotion (pp. 205-227). New York: Academic Press.

Lane, R. D., \& Nadel, L. (Eds.). (2000). Cognitive neuroscience of emotion. New York: Oxford University Press.

Lang, P. J. (1995). The emotion probe: Studies of motivation and attention. American Psychologist, 50, 372-385.

Lang, P. J., Bradley, M. M., \& Cuthbert, B. N. (1997). Motivated attention: Affect, activation and action. In P. J. Lang, R. F. Simons, \& M. Balaban (Eds.), Attention and orienting: Sensory and motivational processes (pp. 97-135). Hillsdale, NJ: Erlbaum.

Lang, P. J., Davis, M., \& Öhman, A. (2002). Fear and anxiety: Animal models and human cognitive psychophysiology. In L. Bäckman \& C. von Hofsten (Eds.), Psychology at the turn of the millennium (Vol. 1, pp. 377-411). Hove, UK: Taylor \& Francis. 
Lazarus, R. S., \& Folkman, S. (1884). Stress, appraisal and coping. New York: Springer.

LeDoux, J. E. (1996). The emotional brain. New York: Pergamon Press.

LeDoux, J. E. (2000). Cognitive-emotional interactions: Listen to the brain. In R. D. Lane \& L. Nadel (Eds.), Cognitive neuroscience of emotion (pp. 129-155). New York: Oxford University Press.

Moltó, J., Montañés, S., Poy, R., Segarra, P., Pastor, M. C., Tormo, M. P., Ramírez, I., Hernández, M. A., Sánchez, M., Fernández, M. C., \& Vila, J. (1999). Un nuevo método para el estudio experimental de las emociones: el International Affective Picture System (IAPS). Spanish adaptation. Revista de Psicología General y Aplicada, 52, 55-87.

Obrist, P. A. (1981). Cardiovascular psychophysiology: A perspective. New York: Plenum Press.

Öhman, A., Hamm, A., \& Hugdahl, K. (2000). Cognition and the autonomic nervous system: Orienting, anticipation, and conditioning. In J. T. Cacioppo, L. G. Tassinary, \& G. G. Berntson (Eds.), Handbook of psychophysiology (pp. 533-575). Cambridge, UK: Cambridge University Press.

Öhman, A., \& Soares, J. J. F. (1994). Unconscious anxiety. Phobic responses to masked stimuli. Journal of Abnormal Psychology, 103, 231-240.

Öhman, A., \& Mineka, S. (2001). Fears, phobias, and preparedness. Toward an evolved module of fear and fear learning. Psychophysiological Review, 108, 483-522.

Pavlov, I. (1927). Conditioned reflexes. Oxford: Oxford University Press.

Pérez, N., Fernández, M. C., Vila, J., \& Turpin, G. (2000). Attentional and emotional modulation of cardiac defense. Psychophysiology, 37, 275-282.

Ramírez, I., Pérez, N., Sánchez, M., \& Vila, J. (1999). Attentional modulation of cardiac defense: External versus internal mechanisms. Psychophysiology, 36, S92.

Reyes, G., Godoy, J., \& Vila, J. (1993). Respiratory sinus arrhythmia as an index of parasympathetic cardiac control during the cardiac defense response. Biological Psychology, $35,17-35$.

Reyes, G., \& Vila, J. (1993). Respiratory influences on the cardiac defense response. International Journal of Psychophysiology, $15,15-26$.

Reyes, G., Vila, J., \& García, A. (1994). Physiological significance of the defense response to intense auditory stimulation: A pharmacological blockade study. International Journal of Psychophysiology, 15, 15-26.

Ruiz-Padial, E. (2003). Modulación emocional de los reflejos defensivos bajo condiciones preatencionales. Unpublished doctoral dissertation, University of Granada, Spain.

Ruiz-Padial, E., Sánchez, M. B., Thayer, J. F., \& Vila, J. (2002). Modulación no consciente de la respuesta cardiaca de defensa por imágenes fóbicas. Psicothema, 14, 739-745.

Sánchez, M. (2000). Modulación emocional de los reflejos de sobresalto y defensa. Unpublished doctoral dissertation, University of Granada, Spain.
Sánchez, M., Ruiz-Padial, E., Pérez, N., Fernández, M. C., Cobos, P., \& Vila, J. (2002). Modulación emocional de los reflejos defensivos mediante visualización de imágenes afectivas. Psicothema, 14, 702-707.

Selye, H. (1956). The stress of life. New York: McGraw-Hill.

Schell, L. M., \& Lieberman, L. S. (1981). Noise stress and cancer. In K. Hammer \& B. H. Newberry (Eds.), Stress and cancer (pp. 202-232). Toronto: Hogrefe.

Sokolov, E. N. (1963). Perception and the conditioned reflex. Oxford: Pergamon Press.

Steptoe, A., \& Vögele, C. (1991). Methodology of mental stress testing in cardiovascular research. Circulation, 83, 14-24.

Thayer, J. F., \& Siegle, G. J. (2002). Neurovisceral integration in cardiac and emotional regulation. IEE Engineering in Medicine and Biology, 21, 24-29.

Turpin, G. (1986). Effects of stimulus intensity on autonomic responding: The problem of differentiating orienting and defense reflexes. Psychophysiology, 23, 1, 1-14.

Turpin, G, \& Siddle, D. A. (1978). Cardiac and forearm plethysmographic responses to high intensity auditory stimulation. Biological Psychology, 6, 267-281.

Turpin, G., \& Siddle, D. A. (1983). Effects of stimulus intensity on cardiovascular activity. Psychophysiology, 20, 6, 611-624.

Vera, M. N., Vila, J., \& Godoy, J. F. (1994). Cardiovascular effects of traffic noise: The role of negative self-statements. Psychological Medicine, 24, 817-827.

Vila, J. (1995). Cardiac psychophysiology and health. In J. Rodríguez-Marín (Ed.), Health psychology and quality of life research (pp. 520-540). Murcia: University of Alicante Press.

Vila, J. (2002). Cardiac defense and emotion: Psychophysiological and clinical implications. In L. Bäckman \& C. von Hofsten (Eds.), Psychology at the turn of the millennium (Vol.1, pp. 413-439). Hove, UK: Taylor \& Francis.

Vila, J., \& Fernández, M. C. (1989). The cardiac defense response in humans: Effects of predictability and adaptation period. Journal of Psychophysiology, 3, 245-258.

Vila, J., Fernández, M. C., \& Godoy, J. (1992). The cardiac defense response in humans: Effects of stimulus modality and gender differences. Journal of Psychophysiology, 6, 140154.

Vila, J., Fernández, M. C., Pérez, M. N., \& Reyes, G. (1996). Autonomic mechanisms underlying the cardiac defense response in humans. Psychophysiology, 33, S87.

Vila, J., Pérez, M. N., Fernández, M. C., Pegalajar, J., \& Sánchez, M. (1997). Attentional modulation of the cardiac defense response in humans. Psychophysiology, 34, 482-487.

Vila, J., Sánchez, M. B., Ramírez, I., \& Fernández, M. C. (1997). Effect of stimulus intensity, rise time, and duration on the cardiac defense response. Psychophysiology, 34, S85.

Watson, J. B., \& Rayner, R. (1920). Conditioned emotional reactions. Journal of Experimental Psychology, 3, 1-14.

Received June 6, 2002

Revision received September 24, 2002 Accepted January 20, 2003 